\title{
Local impact analysis of climate change on precipitation extremes: are high-resolution climate models needed for realistic simulations?
}

\author{
Hossein Tabari ${ }^{1}$, Rozemien De Troch ${ }^{2,5}$, Olivier Giot ${ }^{2,6}$, Rafiq Hamdi ${ }^{2,5}$, Piet Termonia ${ }^{2,5}$, Sajjad Saeed ${ }^{3}$, \\ Erwan Brisson $^{3}$, Nicole Van Lipzig ${ }^{3}$, and Patrick Willems ${ }^{1,4}$ \\ ${ }^{1}$ Hydraulics Division, Department of Civil Engineering, KU Leuven, Kasteelpark Arenberg 40, 3001 Leuven, Belgium \\ ${ }^{2}$ Royal Meteorological Institute of Belgium, Brussels, Belgium \\ ${ }^{3}$ Department of Earth and Environmental Sciences, KU Leuven, Leuven, Belgium \\ ${ }^{4}$ Department of Hydrology and Hydraulic Engineering, Vrije Universiteit Brussel, Brussels, Belgium \\ ${ }^{5}$ Department of Physics and Astronomy, Ghent University, Ghent, Belgium \\ ${ }^{6}$ Plant and Vegetation Ecology, University of Antwerp, Antwerp, Belgium
}

Correspondence to: Hossein Tabari (tabari.ho@gmail.com, hossein.tabari@ kuleuven.be)

Received: 3 March 2016 - Published in Hydrol. Earth Syst. Sci. Discuss.: 7 March 2016

Revised: 17 August 2016 - Accepted: 1 September 2016 - Published: 14 September 2016

\begin{abstract}
This study explores whether climate models with higher spatial resolutions provide higher accuracy for precipitation simulations and/or different climate change signals. The outputs from two convection-permitting climate models (ALARO and CCLM) with a spatial resolution of $3-4 \mathrm{~km}$ are compared with those from the coarse-scale driving models or reanalysis data for simulating/projecting daily and sub-daily precipitation quantiles. Validation of historical design precipitation statistics derived from intensityduration-frequency (IDF) curves shows a better match of the convection-permitting model results with the observationsbased IDF statistics compared to the driving GCMs and reanalysis data. This is the case for simulation of local subdaily precipitation extremes during the summer season, while the convection-permitting models do not appear to bring added value to simulation of daily precipitation extremes. Results moreover indicate that one has to be careful in assuming spatial-scale independency of climate change signals for the delta change downscaling method, as highresolution models may show larger changes in extreme precipitation. These larger changes appear to be dependent on the timescale, since such intensification is not observed for daily timescales for both the ALARO and CCLM models.
\end{abstract}

\section{Introduction}

It becomes evident that climate change will increase the frequency and intensity of extreme events (IPCC, 2007, 2013). Therefore, the impacts of climate change on hydrological extremes such as heavy precipitation events have to be considered when designing and optimizing water infrastructures. The future projection of climate change impact on precipitation usually relies on the simulation results of general circulation models (GCMs). However, these results need to be validated against historical precipitation observations prior to any use for local impact studies of climate change. When GCM results are validated based on observations, sometimes large biases are observed, especially for extreme precipitation values (van Pelt et al., 2012; van Haren et al., 2013; Tabari et al., 2015), imposing an uncertainty on the GCM projections for the future. The biases in the coarse-resolution GCMs come from the fact that they disregard some governing features of precipitation at local scale, next to the scale differences when comparing GCM results with local observations (Maraun et al., 2010; Willems et al., 2012). Some previous studies that attempted to assess GCM skill as a function of resolution showed that the performance of GCMs is independent of their resolution (Johnson et al., 2011; Masson and Knutti, 2011). However, given that deep convective phenomena are sufficiently resolved only at spatial resolutions of up to less than about $4 \mathrm{~km}$, such dynamical downscaling is 
expected to be one of the solutions for decreasing the systematic biases and narrowing the gap between GCM outputs and needs for fine-scale precipitation in hydrological and water engineering studies.

One of the methods to dynamically downscale GCM outputs is to drive a regional climate model (RCM) using a GCM as initial and boundary conditions. RCMs usually provide an improved description of surface features (topographical, land cover, etc.) and more complex description of atmospheric processes compared to GCMs. This often results in more realistic representation of precipitation variability and of climate feedback mechanisms (IPCC, 2001; Mearns et al., 2004; Christensen and Christensen, 2007; Mayer et al., 2015). Whatever climate models are used, verification of their results under the current climate is needed, because some high-resolution RCMs fail to adequately describe local-scale surface processes (especially in inhomogeneous regions with complex topography) due to the convective parameterization scheme or the characteristics of the GCM they are nested in (Hohenegger et al., 2008, and Willems et al., 2012).

High-resolution (convection-permitting resolutions) climate models are of great added value to simulate large convective storms and mesoscale organization (Kendon et al., 2014; Prein et al., 2015). At these resolutions, deep convection is partly resolved and does not need to rely entirely on parameterizations. The representation of the daily cycle in precipitation, extreme events and spatial variability strongly improves for convection-permitting models (Kendon et al., 2012; Prein et al., 2013a, b, 2015; Brisson et al., 2016a; Ban et al., 2014, 2015, Fosser et al., 2015, 2016). However, their long-term simulation is restricted due to high computational costs. They are consequently mainly applied for numerical weather prediction (Done et al., 2004; Baldauf et al., 2011; Tang et al., 2013). The first simulations for decadal time periods using convection-permitting models point to a stronger increase in extremes compared to coarser-resolution integration, but the number of climate change impact studies with these models is limited so far (Hohenegger et al., 2008; Kendon et al., 2012, 2014; Prein et al., 2015).

The use of regional climate models for local impact studies of climate change on precipitation (totals or extremes) has been increased in recent years (e.g., Willems and Vrac, 2011; Olsson et al., 2012, 2015; Mearns et al., 2013; Rajczak et al., 2013). Nevertheless, in some studies, climate scenarios have been based on a broad set of coarse-resolution GCM results (Deng et al., 2013; Rana et al., 2014; Sun et al., 2015). Now, the question is whether high-resolution climate models truly improve extreme precipitation simulations, and, if so, to what extent. This study intends to answer this research question by comparing high-resolution models (RCMs with resolutions between 40 and $3 \mathrm{~km}$ ) with their driving GCM or reanalysis data for simulating sub-daily and daily precipitation quantiles. Further comparisons are performed for simu- lating design precipitation statistics derived from intensityduration-frequency (IDF) curves.

The second research question considered, in case the highresolution climate models show improved extreme precipitation results, is whether this improvement in absolute precipitation values also significantly changes the relative climate change signal. Hydrological applications of climate change impact analysis often assume that the precipitation change factors, defined as the relative change from historical to future climate conditions, can be obtained from GCM or RCM simulations and applied for impact analysis at finer spatial scales. This is the case for any delta change or perturbation based statistical downscaling method (e.g., Ntegeka et al., 2014; Sunyer et al., 2015). In this study, the validity of this hypothesis is investigated by comparing the climate change signals between the high and coarse scale resolution models. Central Belgium is considered as the study location.

\section{Climate models}

\subsection{ALARO model}

The ALARO-0 model is a high-resolution regional climate model developed by the Royal Meteorological Institute (RMI) of Belgium based on the numerical weather prediction model called Aire Limitee Adaptation Dynamique Developpement International (ALADIN). Hereafter, ALARO is used as shorthand name for the ALARO0 model described in De Troch et al. (2013). The ALADIN model is the limited area model (LAM) version of the Action de Recherche Petite Echelle Grande Echelle Integrated Forecast System (ARPEGE-IFS). The physics parameterization package of the ALARO model was designed specifically for running at resolutions between 3 and $8 \mathrm{~km}$. The specific characteristics of the Modular Multiscale Microphysics and Transport (3MT) convection scheme used in the ALARO model lead to a good multiscale performance, particularly in convection-permitting resolutions (De Troch et al., 2013). The ALARO simulations for the present climate conditions over Belgium were performed for the periods 1961-1990 and 1981-2010 at resolutions ranging from $40 \mathrm{~km}$ down to $4 \mathrm{~km}$, both using a set of simulations forced with ERA-40 or ERAInterim reanalysis as well as with the CNRM-CM3 GCM for the historical control run (Table 1). For the future climate projections (2071-2100), the CNRM-CM3 GCM under the A1B scenario was used to force the ALARO model (Hamdi et al., 2014).

\subsection{CCLM model}

The other high-resolution climate model used in this study is the COSMO-CLM (CCLM) model. The CCLM is a nonhydrostatic limited area climate model developed by the climate limited-area modeling (CLM) community. The CCLM model is based on the COSMO model (Steppeler et al., 
Table 1. The convection-permitting model runs used in this study.

\begin{tabular}{llllccc}
\hline $\begin{array}{l}\text { Climate } \\
\text { model }\end{array}$ & $\begin{array}{l}\text { Driving GCM/ } \\
\text { reanalysis }\end{array}$ & $\begin{array}{l}\text { Spatial } \\
\text { scale } \\
(\mathrm{km})\end{array}$ & $\begin{array}{l}\text { Temporal } \\
\text { scale }\end{array}$ & $\begin{array}{c}\text { Control } \\
\text { period }\end{array}$ & $\begin{array}{c}\text { Scenario } \\
\text { period }\end{array}$ & $\begin{array}{l}\text { Data } \\
\text { coverage }\end{array}$ \\
\hline \multirow{5}{*}{ CCLM } & ERA-Interim & 2.8 & 15 min & $2001-2010$ & - & whole year \\
& ERA-Interim & 7 & hourly & $2001-2010$ & - & whole year \\
& ERA-Interim & 25 & 3 hourly & $2001-2010$ & - & whole year \\
& EC-EARTH & 2.8 & 15 min* & $2001-2010$ & $2060-2069$ & whole year \\
& EC-EARTH & 7 & hourly & $2001-2010$ & $2060-2069$ & whole year \\
ALARO & ERA & 3 hourly & $2001-2010$ & $2060-2069$ & whole year \\
\hline & ERA-Interim & 4 & hourly & $1981-2010$ & - & whole year \\
& ENRM-CM3 & 4 & hourly & $1961-1990$ & $2071-2100$ & whole year \\
& ERA40 & 4 & hourly & $1961-1990$ & - & summer \\
& ERA40 & 40 & hourly & $1961-1990$ & - & summer \\
hourly & $1961-1990$ & - & summer \\
\hline
\end{tabular}

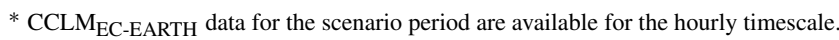

2003), designed by the Deutsche Wetterdienst (DWD) for operational weather prediction. In order to perform climate simulations with the COSMO model, the CLM community provided extensions such as dynamic surface boundaries, a more complex soil model and the possibility of using various $\mathrm{CO}_{2}$ concentration values (Böhm et al., 2006; Rockel et al., 2008).

The model settings are based on a previous study by Brisson et al. (2016a), which provide recommendations for performing climate simulations at a convection-permitting scale. The one-moment microphysical parameterization includes a representation of graupel hydrometeors. In addition, the domain size of this simulation $(192 \times 175$ grid points $)$ is large enough to ensure that the analysis is not affected by the spatial spin-up described in Brisson et al. (2016a). The integration scale of global models largely differs from the convection-permitting scale. A multiple nesting strategy was therefore selected to carry out such simulations (Brisson et al., 2016a, b). A three-step nesting strategy was applied with the driving data, either from ERA-Interim reanalysis data or the EC-EARTH GCM, forcing a CCLM at $25 \mathrm{~km}$ grid mesh size, which in turn forces a CCLM at $7 \mathrm{~km}$ grid mesh size, and next at the final $2.8 \mathrm{~km}$ grid mesh size. Model simulations were performed for the period 2001-2010, and a thorough evaluation of the statistics of precipitation, temperature and cloud characteristics was recently performed (Brisson et al., 2016b). The CCLM driven by EC-EARTH was performed for the period 2000-2010 and 2060-2069 using the RCP4.5 emission scenario (Table 1). Hereafter, the driving GCM or reanalysis dataset is shown as a subscript to the name of the RCM. As the control run of the EC-EARTH GCM ends in 2009, its data for the period 2000-2009 were used for comparing with the driven CCLM simulations.

\section{Methodology}

In this study, simulations of sub-daily and daily precipitation quantiles from the climate models are analyzed. For the future climate analysis, the climate change signals are obtained as relative changes in precipitation intensities calculated as the ratios of precipitation quantiles derived from each climate model scenario simulation over those from the corresponding climate model control simulation with the same nonexceedance probability or return period. This methodology has been applied in several recent climate change studies, e.g., on the basis of statistical downscaling applying quantile mapping or quantile perturbations (Willems and Vrac, 2011; Gudmundsson et al., 2012; Maraun, 2013; Ntegeka et al., 2014; Rana et al., 2014; Sunyer et al., 2015) and also a similar procedure for analyzing the decadal precipitation anomaly (Tabari et al., 2014; Tabari and Willems, 2016). For sub-daily precipitation, independent extremes are selected using a peak over threshold (POT) method. The POT selection is done based on three criteria for inter-event time, interevent low precipitation and peak height, similar to those presented by Willems (2009) for extracting POT values for discharge. The inter-event time is the main criterion for extraction of POT values. Following Willems (2013), an inter-event time of $12 \mathrm{~h}$ is selected, implying that two successive precipitation peaks within the same day or night are considered one extreme event. In other words, two consecutive precipitation extremes are interpreted to be independent based on this criterion when the time between the two events exceeds $12 \mathrm{~h}$. Extreme precipitation is defined in this study as precipitation with a return period $(T)$ higher than 1 year. The return period is in this study calculated in two different ways: empirically based on the rank of the extracted POT values $(n / i$, where $n$ and $i$ are the length of the study period and rank, respectively; $i=1$ for the highest value), and theoretically 

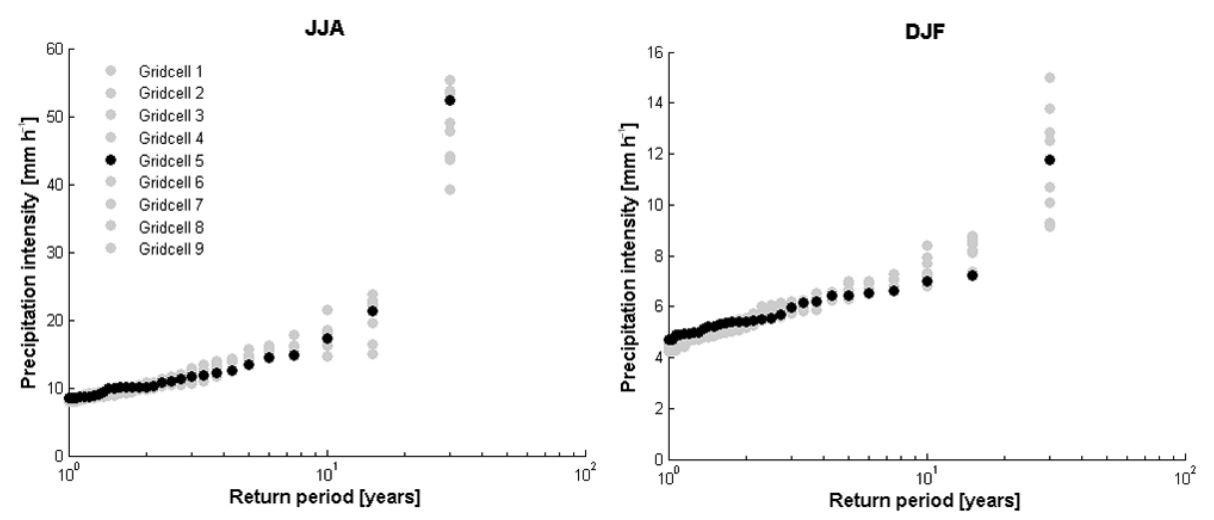

Figure 1. Hourly precipitation extremes in a matrix of $3 \times 3$ ALARO $_{\text {ERA-Interim }} 4 \mathrm{~km}$ model grid points surrounding the closest model grid point to Uccle (Gridcell 5), for the summer (left panel) and winter (right panel) seasons (historical climate: 1961-1990).

after calibrating an extreme value distribution to these POT precipitation extremes. Also, for the calculation of the precipitation change factors for given return periods, these two different approaches were followed and compared: empirical data based and extreme value distribution based change factors. For the distribution based change factors, first a distribution is fitted separately to the extreme values of the control and scenario runs of the climate models. Afterwards, change factors are computed as a ratio between the fitted distribution values of the scenario and control runs.

In addition to the quantile analysis, the historical simulations of the climate models are validated based on precipitation intensity-duration-frequency (IDF) curves that are typically used for design storm calculations and related designs, e.g., urban drainage systems and hydraulic structures. The IDF curves for 1-month, 1-year and 10-year return periods and for durations from 10-15 min up to 1 month are developed for the control runs of the climate models as well as the observations. The IDF curves are derived based on POT extreme value statistics after calibration of two-component exponential distributions, following Willems (2000). In this paper, the precipitation intensities of given return periods are referred to as design precipitation quantiles.

For the climate models, precipitation data are extracted from a matrix of $3 \times 3$ model grid points (nine cells) surrounding the closest model grid point to Uccle station in central Belgium. This station is selected because it has highquality $10 \mathrm{~min}$ observations recorded with the same instrument since 1898 (Demarée, 2003). In addition to the $10 \mathrm{~min}$ station observations, daily E-OBS gridded data (v12.0, Haylock et al., 2008) for 27.8 and $55.7 \mathrm{~km}$ are used. These gridded data are aggregated to larger pixels of 167 and $334 \mathrm{~km}$ to be consistent with the grid mesh size of the driving GCMs and reanalysis data. The aggregation is also performed to upscale the outputs of the convection-permitting climate models to check the accuracy of the spatial structure in the models.

\section{Validation of precipitation simulations}

The capability of the climate models to simulate the presentday precipitation is evaluated before investigating future precipitation changes. Prior to this performance evaluation, the precipitation extremes from the model grid cell covering Uccle station are compared with those from neighboring cells for possible outlier or unrealistic values. The analysis shows spatial consistency in the frequency of daily and sub-daily precipitation extremes for both the ALARO and CCLM models. As an example, Fig. 1 illustrates hourly precipitation extremes in a matrix of $3 \times 3$ ALARO ERA-Interim $4 \mathrm{~km}$ model grid points surrounding the closest model grid point to Uccle station for the summer and winter seasons. It is seen that hourly precipitation extremes in grid cell 5 covering Uccle station are consistent with the ones in the neighboring grid cells. Another preliminary analysis is performed to compare point and pixel interpolated Uccle precipitation observations, which are used as a reference for the model performance evaluation (Fig. 2). The comparison is done for the periods 1961-1990 and 2001-2010, which are the control periods of the ALARO and CCLM models, respectively. The precipitation extremes from the pixel E-OBS data follow the pattern of the point observations and the extremes are well represented in the pixel dataset. The smaller amounts from the gridded dataset are due to the fact that spatial averaging smooths out the extreme values (Hofstra et al., 2009; Sunyer et al., 2013).

The validation results of the daily precipitation quantiles simulated by the ALARO convection-permitting models and their boundary conditions based on the point and pixel interpolated Uccle observations for the summer season (JuneJuly-August: JJA) are shown in Fig. 3. The precipitation extremes for each model run are evaluated on the native model grids, and are then aggregated to a larger model grid size in order to ensure a fair comparison. For the aggregation purpose, the coarsest grid is used as a reference. It means that, for instance for the ALARO model, the evaluation of the model with 4 and $10 \mathrm{~km}$ resolutions is carried out on the 

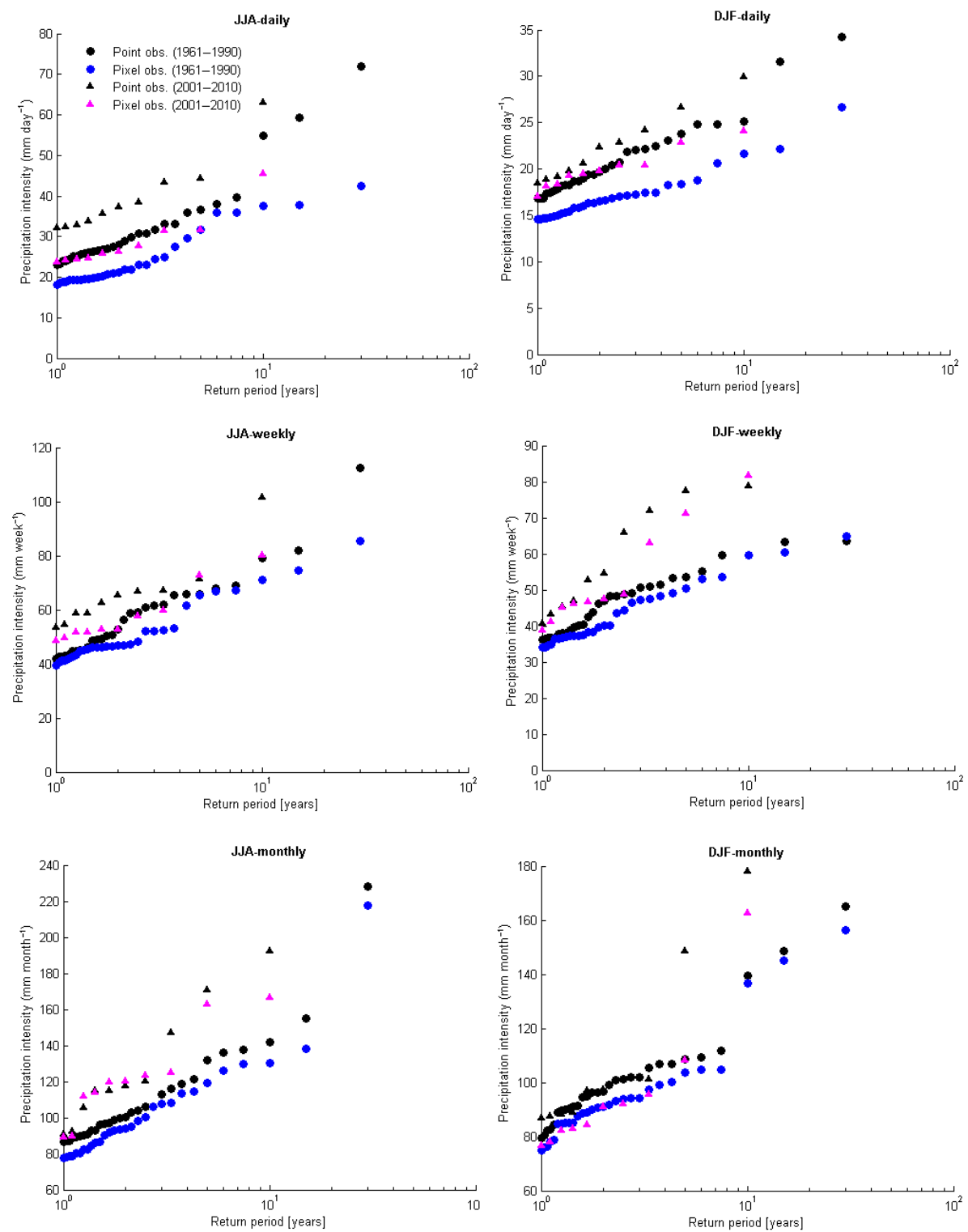

Figure 2. Comparison between point and pixel interpolated (spatial resolution of $27.8 \mathrm{~km}$ ) Uccle precipitation of different timescales for summer (left-column panels) and winter (right-column panels).

coarser $40 \mathrm{~km}$ grid. The results on the native model grids are presented to evaluate whether the available climate model runs are of direct use for climate change impact analysis in urban hydrology. The native daily precipitation extremes reveal the largest extreme values for the ALAROERA40 $4 \mathrm{~km}$ model (Fig. 3a). However, this might be due to the precipitation decrease after the spatial averaging. The overestimation of the ALARO runs nested in the ERA40 reanalysis data is also evident on the native model grids, while the extreme simulations of the $\mathrm{ALARO}_{\mathrm{CNRM}-\mathrm{CM} 3}$ model with $4 \mathrm{~km}$ resolution are in between the point observations and the gridded ones, with a grid size of $27.8 \mathrm{~km}$, which shows the good accuracy of these simulations. When comparing the model results at the same grid size (Fig. 3b), the ALARO ERA40 $40 \mathrm{~km}$ outputs are larger than those from the ALARO ERA40 model for the higher resolutions at 4 and $10 \mathrm{~km}$. This indicates the role of spatial scale in the climate modeling by the ALARO model driven by the ERA40 reanalysis data. Also, other authors reported no improvements in the simulations of daily mean precipitation by the convection-permitting models compared with large-scale climate models (Chan et al., 2013; Fosser et al., 2015). Some other researchers found improvements, especially over mountainous areas (Prein et al., 2013b; Ban et al., 2014), implying region and model dependency for simulation of daily mean precipitation. In our study, the higher skill of the $\mathrm{ALARO}_{\mathrm{CNRM}-\mathrm{CM} 3}$ model in sim- 

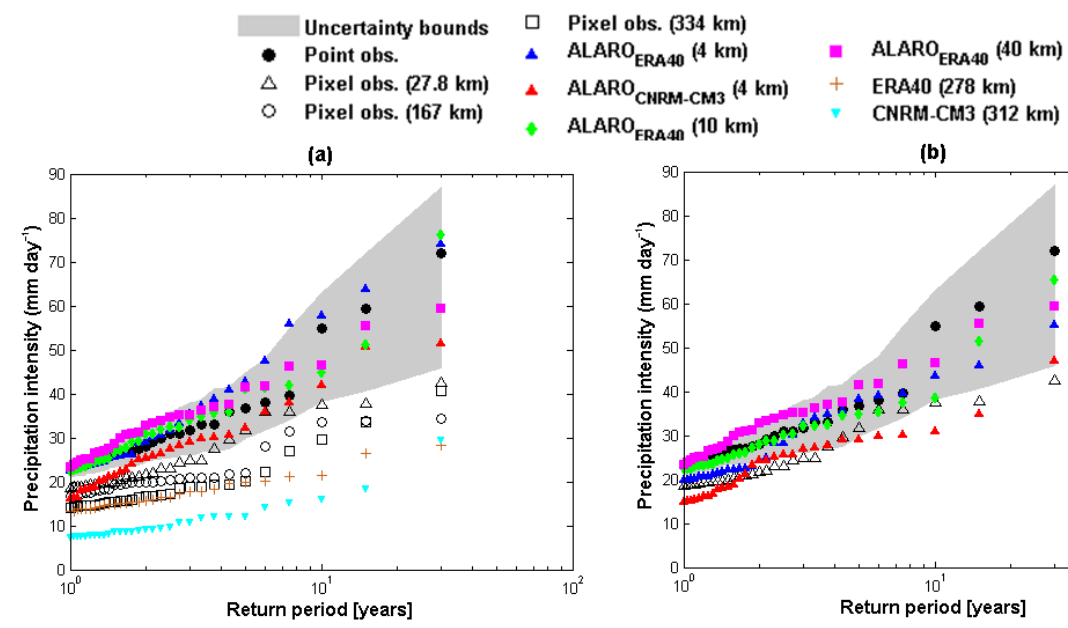

(b)

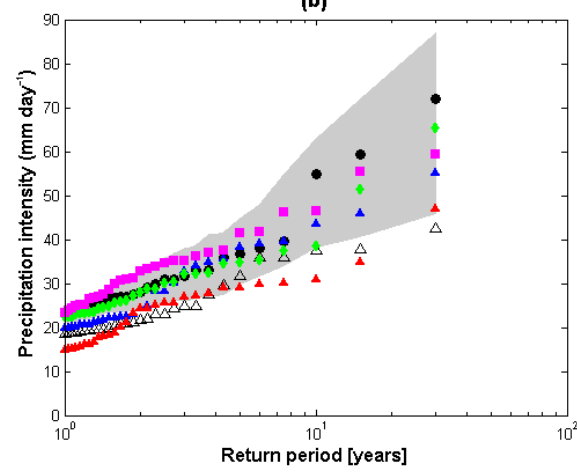

Figure 3. Validation of the native (a) and aggregated (b) daily precipitation quantiles (1961-1990) for the ALARO model and its driving GCM or reanalysis data based on Uccle observations, for the summer season (shaded areas show at-site confidence intervals for the point observations using the bootstrap-based $95 \%$ confidence intervals).
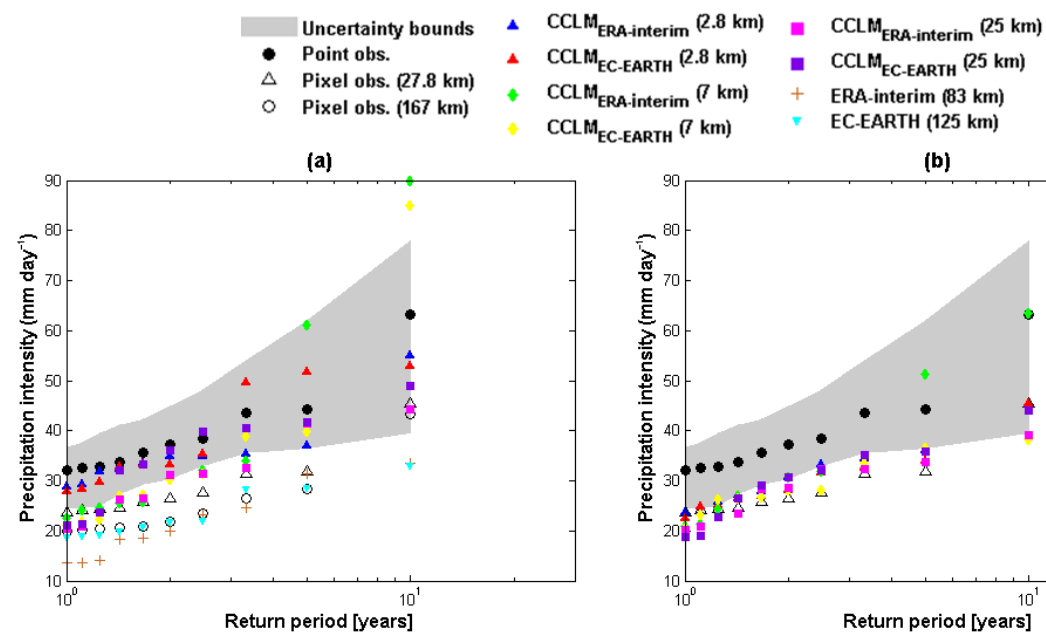

(b)

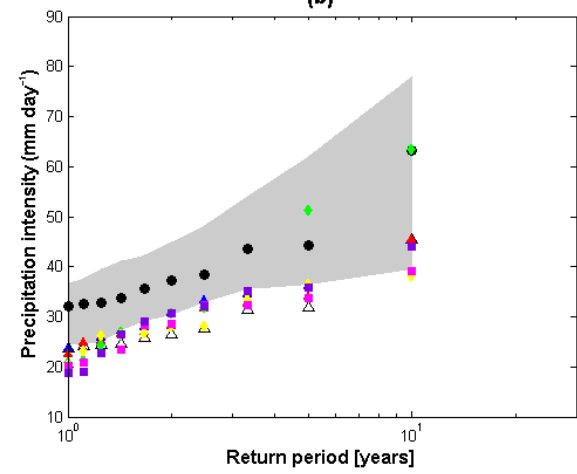

Figure 4. Validation of the native (a) and aggregated (b) daily precipitation quantiles (2001-2010) for the CCLM model and its driving GCM or reanalysis data based on Uccle observations, for the summer season (shaded areas show at-site confidence intervals for the point observations using the bootstrap-based $95 \%$ confidence intervals).

ulation of summer precipitation extremes appears to be because of a better representation of the small-scale characteristics and spatial variability relevant for convection (Fig. 3b). The CNRM-CM3 GCM and ERA40 reanalysis data used as the boundary conditions of the ALARO model show a systematic underestimation, especially for the higher return periods (Fig. 3a). The convection parameterization has been found to be responsible for this underestimation (Kendon et al., 2014).

As for the CCLM model, the native daily precipitation quantiles from the $2.8 \mathrm{~km}$ runs are larger for most of the cases (Fig. 4a). After upscaling of the finer-resolution models $(2.8$ and $7 \mathrm{~km})$ to the larger scale $(25 \mathrm{~km})$, the results of the models become similar (Fig. 4b). The driving EC-EARTH
GCM and ERA-Interim reanalysis underestimate the summer extremes, probably due to the misrepresentation of the convective processes. When the results of the driven GCM and reanalysis data are compared with the ones of the CCLM, the larger and more accurate simulations of the CCLM model are observed for summer, when convection becomes dominant. This confirms the finding that higher resolution results in more extreme precipitation in climate models (Jacob et al., 2014). The increasing skill of RCMs with increasing model resolution for simulation of the spatio-temporal characteristics of summer precipitation has been found by using the high-resolution models, although it is limited in application (Rauscher et al., 2010; Kendon et al., 2012). Nevertheless, a comparison between the CCLM outputs of different resolu- 

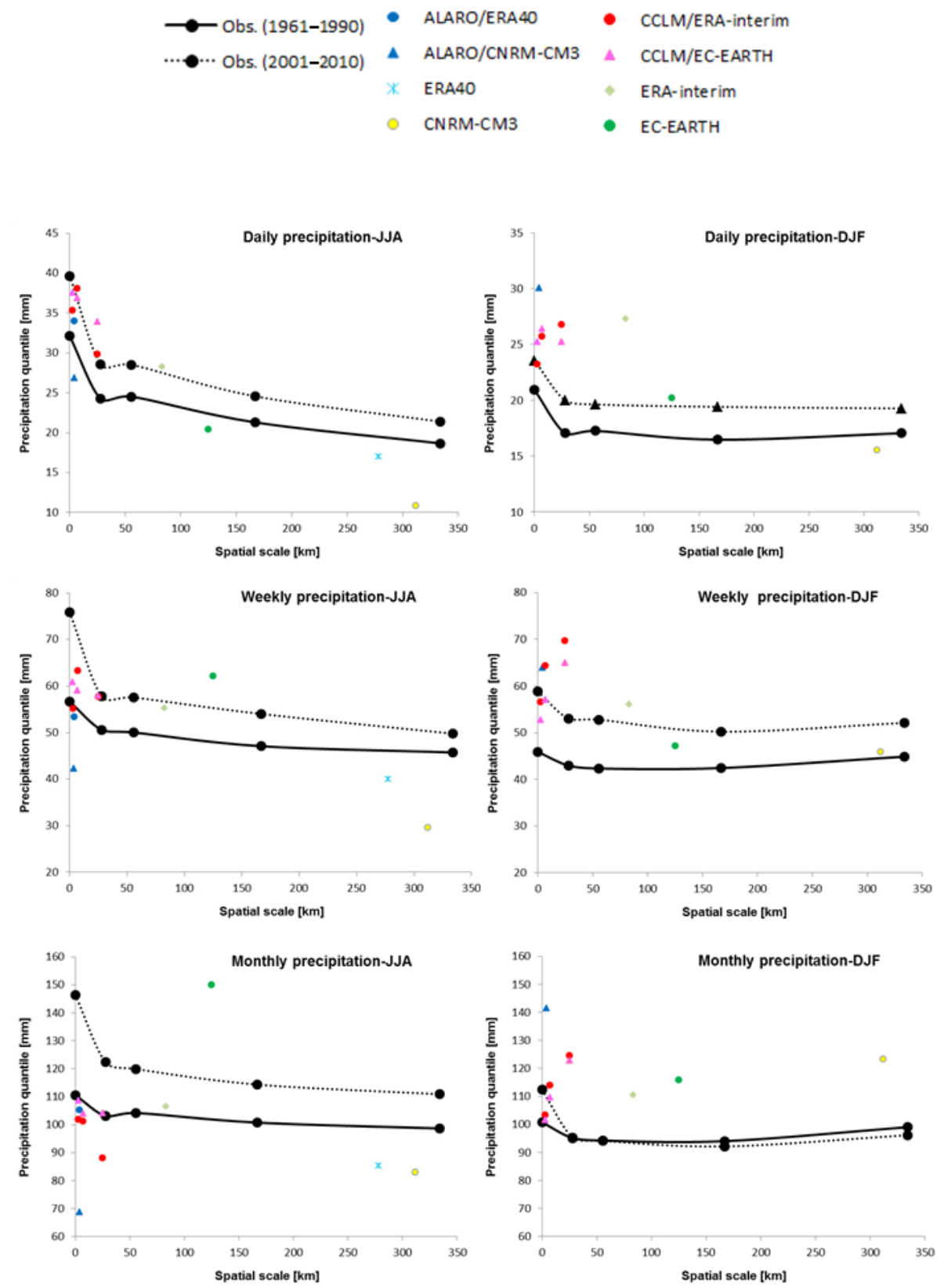

Figure 5. Validation of the extreme precipitation (averaged over the extreme events with $T>1$ year) simulations for ALARO, CCLM and the driving GCMs or reanalysis data based on point and pixel interpolated Uccle observations for the summer (left panels) and winter (right panels) seasons, vs. the models' spatial scale.

tions does not show a clear difference, either in precipitation intensity or in simulation skill (Fig. 4b).

The extreme precipitation (averaged over the extreme events with $T>1$ year) simulations of the climate models vs. spatial scales for both the summer and winter seasons are shown in Fig. 5. Taking the spatial scale difference into account and averaging the extreme values with $T>1$ year, the $\mathrm{ALARO}_{\mathrm{ERA} 40}$ simulations are closer to the observations compared with the ALARO CNRM-CM3 $_{3}$ model. A decease in systematic biases in the large-scale climate in reanalysisdriven RCM simulations was also reported by Maraun et al. (2010). They also pointed out that these RCMs are capable of reproducing the actual day-to-day sequence of weather events. The good accuracy of the CCLM model, large underestimations of CNRM-CM3 and EC-EARTH, slight overestimation of ERA-Interim data and slight underestimation of ERA40 data for summer precipitation extremes are also obvious from these plots. As expected, the percentage bias of 


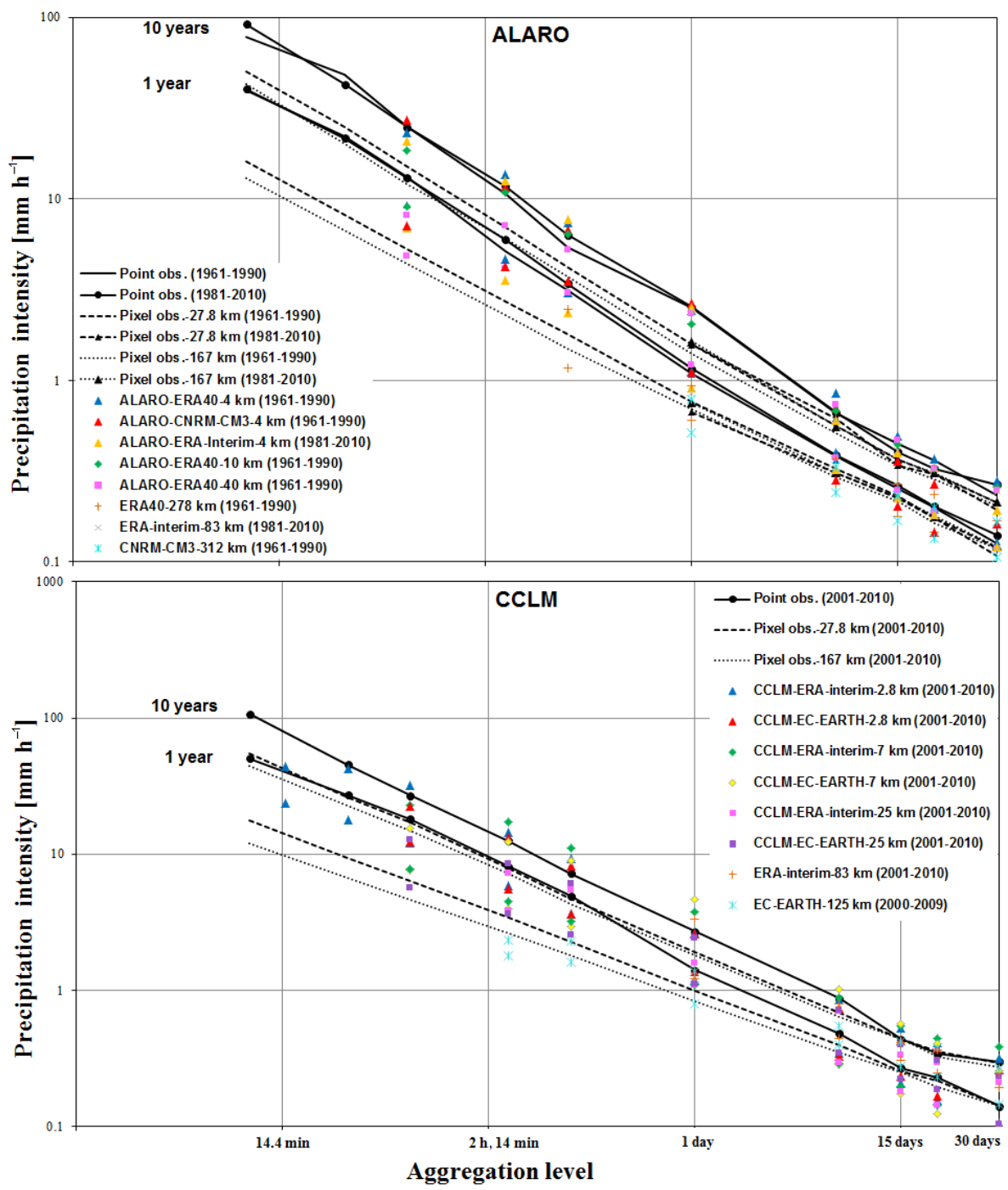

Figure 6. Comparison of historical IDF relationships based on point and pixel interpolated Uccle observations, with CCLM, ALARO and the driving GCM or reanalysis results for the summer season (IDF curves for the E-OBS pixel data were extrapolated for the sub-daily timescales based on extreme value distribution).

the climate models (not shown) decreases as the timescales get larger (i.e., weekly and monthly).

The validation of the climate model simulations for the summer season in terms of IDF statistics is shown in Fig. 6 for timescales in the range between $10-15$ min and 30 days. The IDF curves are plotted with reference to design precipitation intensities from the station and E-OBS pixel data over the Uccle location (central Belgium). Comparing the hourly simulations of the ALARO ERA40 model with different resolutions shows the greater intensities for finer resolutions. In terms of accuracy, all of the ALARO runs except the ALARO $_{\text {CNRM-CM3 }}$ for the 10-year return period and the ALARO ERA40 $40 \mathrm{~km}$ for both return periods underestimate the station observations and overestimate the gridded observations (extrapolated for sub-daily precipitation based on extreme value distribution). Regarding 3- and 6-hourly timescales, the ALARO model simulates more intense precipitation of the 10-year return period in comparison to both the station and gridded observations. The model underestimates (overestimates) extreme precipitation of the 1-year return period and 3- and 6-hourly durations when compared with the station (gridded) observations. Daily precipitation intensity of the 10-year return period derived from the point observations is underestimated by the ALAROERA40 and ALAROERA-Interim runs and overestimated by the $\mathrm{ALARO}_{\mathrm{CNRM}-\mathrm{CM} 3}$ run, while all the runs overestimate the pixel observation-based statistics. All the ALARO runs except the ALARO ERA-Interim simulate larger daily precipitation extremes of the 1-year return period. A comparison between the ALARO $4 \mathrm{~km}$ runs 
nested in reanalysis data for larger timescales between 5 and 30 days shows overestimation of the ALARO ERA40 and underestimation of the ALAROERA-Interim with respect to the station data, whereas both of them overestimate the pixel observation-based statistics. The other ALARO $4 \mathrm{~km}$ run $\left(\mathrm{ALARO}_{\mathrm{CNRM}-\mathrm{CM} 3}\right)$ underestimates both the point and pixel observation-based statistics for these larger aggregation levels (5, 10, 15 and 30 days).

The CCLM model simulates less intense 15 min precipitation of a 10-year return period (Fig. 6). However, this underestimation changes to overestimation for larger sub-daily aggregation levels. For the sub-daily design storms of the 1-year return period, the CCLM model generally underestimates the station observations, while both overestimations and underestimations are seen in comparison with the gridded observations. However, the EC-EARTH GCM extremely underestimates both the gridded and rain-gauge observations for the 10-year return period. This supports the recent findings for underestimation of heavy hourly precipitation during summer by large-scale climate models and more accurate simulations of convection-permitting models (Chan et al., 2013, 2014; Ban et al., 2014; Fosser et al., 2015). In the case of daily duration, which are less important for urban drainage applications, the CCLM runs underestimate (overestimate) the precipitation intensity of the 1-year return period in comparison with the point (gridded) observations (Fig. 6). The underestimation of higher intensities by the CCLM $2.8 \mathrm{~km}$ run for summer has also been reported in the literature (Fosser, 2014). For the daily precipitation extremes of 10 -year return period, the $2.8 \mathrm{~km}$ runs and the CCLM EC-EARTH $25 \mathrm{~km}$ underestimate (overestimate) precipitation intensity from the point (gridded) observations, while the rest of the CCLM runs show the opposite behavior. For the larger aggregation levels between 5 and 30 days, the precipitation intensities of the 1-year return period derived from both the point and pixel observations are underestimated by all the CCLM runs. For the 5-day duration and 10-year return period, underestimation of the station observation-based statistics and overestimation of the pixel observation-based statistics are seen for all the CCLM runs except for the $7 \mathrm{~km}$ runs. The CCLM $M_{\text {ERA-Interim }} 2.8$ and $7 \mathrm{~km}$ runs simulate larger precipitation extremes for the 10-, 15- and 30-day durations of the 10-year return period, whereas the CCLMERA-Interim $25 \mathrm{~km}$ run simulates smaller extremes. The similarity between the CCLM 2.8 and $7 \mathrm{~km}$ runs is expected to be explained by the similarity in lateral boundary conditions since the CCLM $2.8 \mathrm{~km}$ model is nested in the CCLM $7 \mathrm{~km}$ model. However, the difference between these runs becomes obvious when the convection is dominant in sub-daily summer precipitation, as they treat deep convection in different ways.

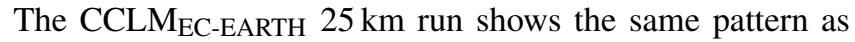
the CCLM ERA-Interim run: underestimation of extreme precipitation intensity for the 10-, 15- and 30-day durations of the 10-year return period. Both overestimations and underestimations are seen for the CCLM $\mathrm{EC}_{\mathrm{E}-\mathrm{EARTH}} 2.8$ and $7 \mathrm{~km}$ runs for the 10-, 15- and 30-day durations of the 10-year return period (Fig. 6).

For the winter season (December-January-February: DJF), the results show overestimations of the ALARO and CCLM models (Fig. 5). As winter precipitation over Belgium is mainly controlled by large-scale circulation, an improvement in the simulations of convection-permitting models in comparison to the parent large-scale models is less expected for the winter season. Although improved simulations of winter precipitation by the convection-permitting model have been reported for regions with complex topography (Ikeda et al., 2010; Rasmussen et al., 2011) due to better resolved orography (Prein et al., 2015), this effect is less relevant for Belgium, which is more flat. Whereas winter daily precipitation extremes are systematically overestimated by the ALARO model, the driving CNRM-CM3 GCM slightly underestimates the winter extremes (Fig. 5). Deficiency of very high-resolution climate models in simulation of winter precipitation extremes is because the fronts and synoptic depressions that cause the dynamical processes driving winter precipitation events have scales of $10^{2}-10^{3} \mathrm{~km}$. This deficiency has been demonstrated by Hong and Leetmaa (1999) and Chan et al. (2013). For the CCLM model, when the CCLM $_{\text {EC-EARTH }} 2.8$ and $7 \mathrm{~km}$ simulations are compared with those of the CCLMERA-Interim 2.8 and $7 \mathrm{~km}$ for the daily winter extremes, the overestimations of the earlier runs are higher than the later ones, while for larger timescales (weekly and monthly) the opposite pattern is observed.

\section{Future precipitation changes}

To cope with the scale difference and the biases shown in the previous section, state-of-the-art climate change impact analysis makes use of statistical downscaling. One of the popular downscaling methods is the delta change method. Different versions exist for that method, from the simple basic method to more advanced methods such as the quantile perturbation method. In this type of method, the intrinsic assumption is made that the bias under future climate conditions is identical to the bias in current climate conditions. This is implemented through the use of "change factors" applied for historical precipitation quantiles. Another important assumption that is made by these methods is that the change factors are spatial scale-independent, such that the scale difference, although it is an issue for the absolute precipitation intensity values, is less an issue for the delta change methods at which relative changes are applied. The latter assumption is tested next. In this context, the relative changes in precipitation quantiles between the future and historical simulations of climate model runs were calculated to compare the convectionpermitting models and their driving GCMs. These change factors were computed for the winter and summer seasons as sub-daily and daily precipitation quantiles from the scenario period divided by those from the control period with 
the same return period (a change factor equal to 1 means no change).

The change factors derived from the empirical data, and the ones after use of the extreme value distribution in precipitation extremes for the winter and summer seasons computed by the $\mathrm{ALARO}_{\mathrm{CNRM}-\mathrm{CM} 3}$ model and the driving CNRMCM3 GCM, are shown in Fig. 7. From a comparison between the empirical data based change factors and those based on the extreme value distributions, it is seen that the extreme value distribution fitting smooths out abrupt changes and random variations in the change factors, making the results easier to interpret. In fact, the distribution fitting removes the randomness involved in the high return periods of the empirical data for summer, leading to a slight difference in the range of changes. However, for the winter season the change factors from the two methods have similar ranges. The change factors obtained from the extreme value distribution fitting are further discussed here. The $\mathrm{ALARO}_{\mathrm{CNRM}-\mathrm{CM} 3}$ projects an increasing signal in the range of 26 to $69 \%$ for daily winter extremes. The projected increase is even higher for hourly winter extremes, ranging between 37 and $120 \%$. When the change factors computed by the $\mathrm{ALARO}_{\mathrm{CNRM}} \mathrm{CM} 3$ are compared with those obtained from the driving CNRM-CM3 GCM, more or less the same conclusion can be made: an increasing signal for daily winter extremes between 23 and $67 \%$. For the summer season, the change factors from the $\mathrm{ALARO}_{\mathrm{CNRM}-\mathrm{CM} 3}$ model and the parent CNRM-CM3 GCM are around 1, meaning no change in daily summer extremes. However, smaller hourly summer extremes are expected based on the $\mathrm{ALARO}_{\mathrm{CNRM}-\mathrm{CM} 3}$ model projections, with a decreasing signal down to $-26 \%$. Generally, it can be inferred from the results that, at the synoptic (daily) scale, the projections by the ALARO model are consistent with those from the driving GCMs. De Troch et al. (2013) pointed out that an increase in spatial resolution in the ALARO model is not as important as the parameterization scheme used for extreme precipitation modeling at the daily scale.

Figure 8 shows the change factors for daily and 3-hourly precipitation computed using the CCLM EC-EARTH model with different spatial resolutions and the driving EC-EARTH GCM for the winter and summer seasons. The change factors for all extreme events with $T>1$ year are shown in this figure. For the winter season, the change factors for both daily and 3-hourly precipitation decrease as the model's resolution increases. Nevertheless, the change factors for all the CCLM runs are higher than those for the driving EC-EARTH GCM. A larger change is projected for 3-hourly precipitation compared with daily precipitation. For summer, the greatest change is obtained for 3-hourly precipitation extremes from

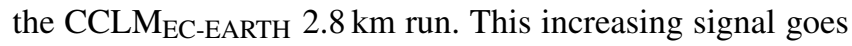
as high as $55 \%$. When the change factors in 3-hourly precipi-

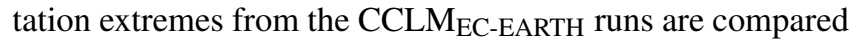
with those from the driving EC-EARTH GCM, the results show an amplification of the future climate change signals by the CCLM model: maximum changes of 55, 11 and $14 \%$, respectively, for $2.8,7$ and $25 \mathrm{~km}$ runs vs. a maximum change of $8 \%$ for the driving EC-EARTH GCM. This amplification is not evident for the daily scale. Intensification of change in sub-daily precipitation extremes that are not simulated by large-scale models was also found by Kendon et al. (2014). The results also reveal that sub-daily precipitation extremes during summer are expected to change at a higher rate compared to daily extremes. Generally, it can be inferred that there is an increase in the change factors of sub-daily precipitation when going from parameterized convection to the convection-permitting scale.

\section{Concluding remarks}

A comparative study between the convection-permitting climate models with a spatial resolution from 2.8 up to $40 \mathrm{~km}$ and driving GCMs or reanalysis data was performed to check whether the models with higher resolution provide more accurate precipitation simulations. Another analysis was performed to validate the spatial-scale independency assumption of climate change signals for the delta change downscaling method. The results show that, whereas winter daily precipitation extremes are generally overestimated by the ALARO and CCLM models, improved results for summer precipitation extremes are observed, especially for sub-daily timescales. This suggests the added value of convectionpermitting climate models to simulate summer sub-daily extremes because of either better representation of deep convection or more detail of the land surface. The results moreover indicate that the difference between the convectionpermitting models and the parent GCMs or reanalysis data decreases as the timescales get larger (i.e., weekly and monthly). Based on the precipitation statistics derived from IDF curves, the ALARO and CCLM models mostly underestimate local sub-daily precipitation, but still better simulate it compared with parent GCM or reanalysis data when available. Higher precipitation intensities by finer-resolution models are a result of better representation of small-scale convective precipitation by these models.

To investigate whether or not the climate change signals from the convection-permitting models are more or less the same as those from the large-scale driving GCMs, the relative changes were computed for precipitation extremes during summer and winter. For the ALARO model, it can be concluded that, at a synoptic (daily) scale, the change factors for the ALARO model are comparable with the ones from the driving CNRM-CM3 GCM. In the case of the CCLM model, the results reveal an intensification of climate change signals for the CCLM model compared with the driving ECEARTH GCM for the 3-hourly timescale. Comparing change factors for 3-hourly and daily precipitation, a larger change is projected for 3-hourly precipitation for both the winter and summer seasons. When the change factors derived from 

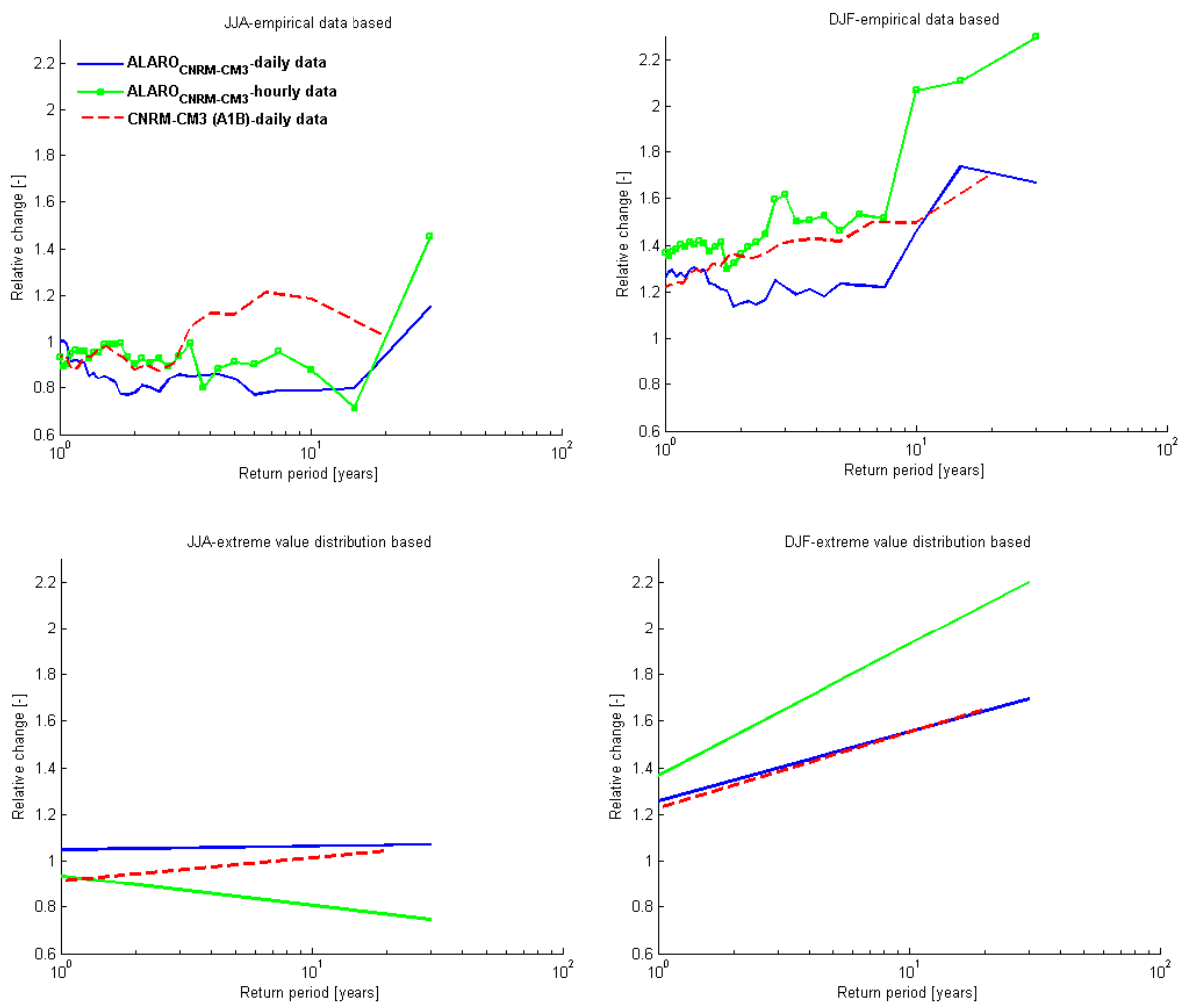

Figure 7. Change factors for daily and hourly precipitation quantiles computed using the ALARO $\mathrm{CNRM}_{\mathrm{CM} 3} 4 \mathrm{~km}$ and the driving CNRMCM3 (A1B) for the summer (left-column panels) and winter (right-column panels) seasons, obtained from the empirical data (top panels) and after use of the extreme value distributions (bottom panels).

the extreme value distribution are compared with those from the empirical data, it is seen that for both the ALARO and CCLM models the climate change signals derived from extreme value distribution fitting are slightly different from the ones obtained from the empirical data for summer due to the removed randomness in the empirical data by the distribution fitting. However, for the winter season the change factors obtained from the two approaches cover more or less the same range.

In summary, because the results of this study indicate that the local sub-daily summer precipitation simulations of the high-resolution climate models are closer to the observations, their future projections are expected to be more accurate than those of the driving GCMs. These climate change signals obtained from the high-resolution models may differ from the ones based on the coarse-resolution models, as a result of improved representation of complex landscape and land surface processes in high-resolution models. However, the resulting precipitation change from these high-resolution climate models should not be interpreted as an exact number, because of their limited number. More runs with high-resolution models are required to check the consistency among models. In the same way as an ensemble approach on climate models provides uncertainty estimates on the climate change signals, an ensemble of the high-resolution models provides uncer- tainty estimates on the difference between the climate change signals of fine vs. coarse scale. Also, the statistical significance of the difference in climate change signals at fine vs. coarse scale can be tested in such an approach. From the comparison in this study, the results of the CCLM EC-EARTH $_{\text {I }}$ model indicate an increase in the change factors in sub-daily summer extremes when going from parameterized convection to the convection-permitting scale. This amplification is not evident at the daily timescale. For the ALARO model the higher-resolution models also show changes in the same range as the coarse-resolution models for daily precipitation. The differences appear to be a function of timescale, season and climate model. Different procedures for convection parameterization in the CCLM and ALARO models and different boundary conditions (the first one is nested in the ECEARTH model from CMIP5 and the latter in the CNRMCM3 model from CMIP3) might explain the discrepancy between the results of the two models. The differences in timescale and season are expected to be explained by a more realistic simulation of the mesoscale processes involved during sub-daily summer precipitation extremes by convectionpermitting models. The results also show an amplification of the change from daily to sub-daily precipitation for both the ALARO and CCLM models, which casts doubt on the 

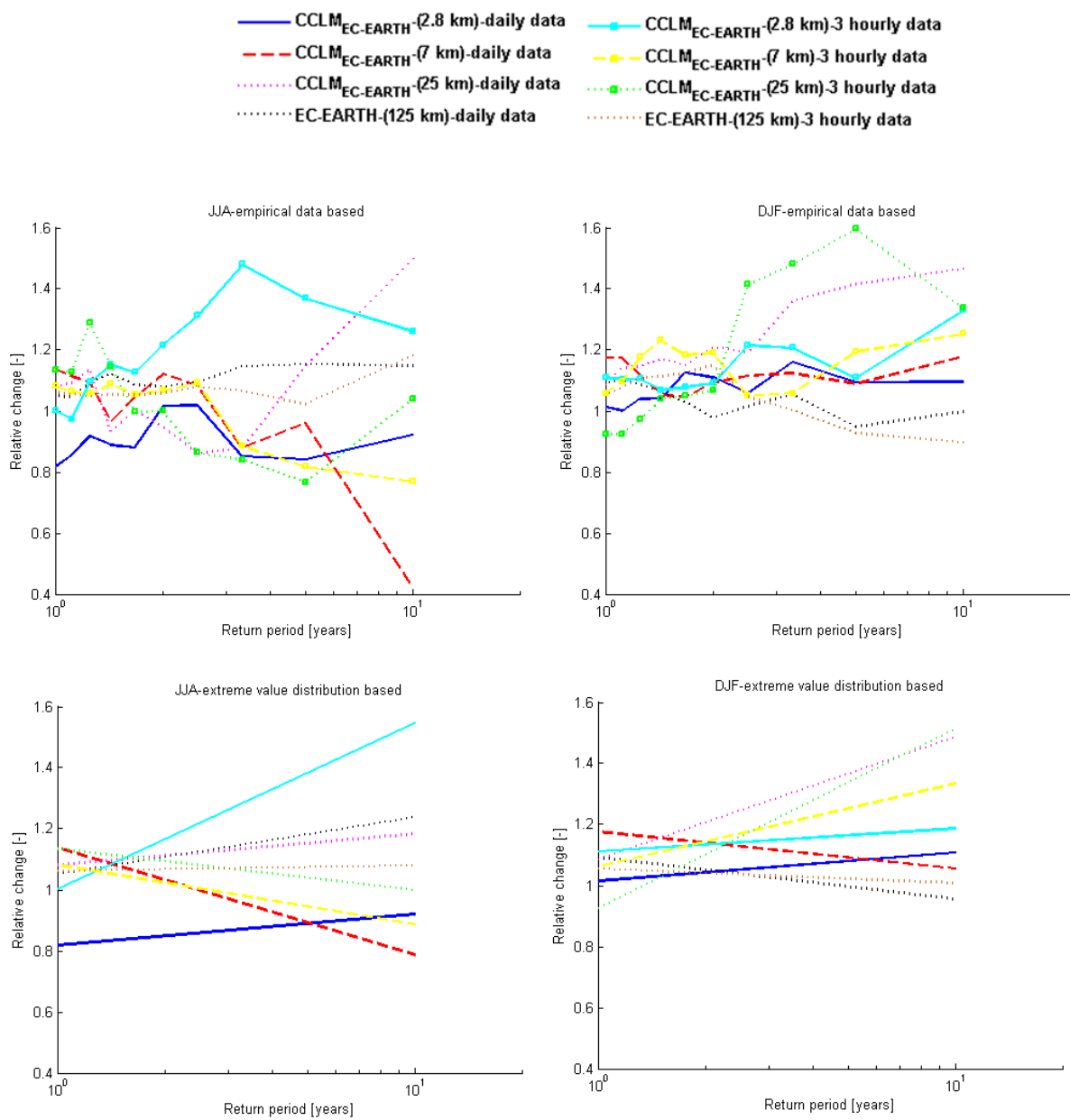

Figure 8. Change factors for daily and 3-hourly precipitation quantiles computed using CCLM $\mathrm{EC}_{\text {EARTH }} 2.8,7$, and $25 \mathrm{~km}$ for the summer (left-column panels) and winter (right-column panels) seasons, obtained from the empirical data (top panels) and after use of the extreme value distributions (bottom panels).

validity of the temporal-scale independency assumption of climate change signals.

\section{Data availability}

The E-OBS data are freely available at the website of the European Climate Assessment and Data (http://www.ecad. eu/download/ensembles/download.php). The reanalysis data are publicly available from the European Centre for MediumRange Weather Forecasts (ECMWF) (http://www.ecmwf. int/en/research/climate-reanalysis). The historical precipitation time series were provided by the Royal Meteorological Institute (RMI) of Belgium (http://www.meteo.be/meteo/ view/en/65239-Home.html). The high-resolution ALARO and CCLM data are not publicly available.

Author contributions. The simulations of the ALARO climate model were performed in the Royal Meteorological Institute of Belgium (RMI) by Rozemien De Troch, Olivier Giot, Rafiq Hamdi and
Piet Termonia. The CCLM climate model was implemented by Sajjad Saeed, Erwan Brisson and Nicole Van Lipzig in the Earth and Environmental Sciences Department of KU Leuven. H. Tabari and P. Willems developed the methodology and performed the analyses. The paper was prepared by Hossein Tabari and Patrick Willems with substantial contributions from all co-authors.

Acknowledgements. This study was partly supported by research projects for the Flemish Environment Agency (Division Operational Water Management and Environmental Reporting), and partly by the Belgian Science Policy Office (CORDEX.be project, BRAIN-be program) and the European Union's Horizon 2020 research and innovation program (project BRIGAID, grant agreement no. 700699).

Edited by: M.-C. ten Veldhuis

Reviewed by: J. Olsson and K. Arnbjerg-Nielsen 


\section{References}

Baldauf, M., Seifert, A., Förstner, J., Majewski, D., Raschendorfer, M., and Reinhardt, T.: Operational convective-scale numerical weather prediction with the COSMO model: Description and sensitivities, Mon. Weather Rev., 139, 3887-3905, doi:10.1175/MWR-D-10-05013.1, 2011.

Ban, N., Schmidli, J., and Schar, C.: Evaluation of the convectionresolving regional climate modeling approach in decadelong simulations, J. Geophys. Res.-Atmos., 119, 7889-7907, doi:10.1002/2014JD021478, 2014.

Ban, N., Schmidli, J., and Schär, C.: Heavy precipitation in a changing climate: Does short-term summer precipitation increase faster?, Geophys. Res. Lett., 42, 1165-1172, doi:10.1002/2014GL062588, 2015.

Böhm, U., Kücken, M., Ahrens, W., Block, A., Hauffe, D., Keuler, K., Rockel, B., and Will, A.: CLM - The Climate Version of LM : Brief Description and Long-Term Applications, COSMO Newsletters, 6, 225-235, 2006.

Brisson, E., Demuzere, M., and van Lipzig, N. P. M.: Modelling strategies for performing convection-permitting climate simulations, Meteorol. Z., 25, 149-163, 2016 a.

Brisson, E., Van Weverberg, K., Demuzere, M., Devis, A., Saeed, S., Stengel, M., and van Lipzig, N. P. M.: How well can a convection-permitting climate model reproduce decadal statistics of precipitation, temperature and cloud characteristics?, Clim. Dynam., doi:10.1007/s00382-016-3012-z, in press, 2016b.

Chan, S. C., Kendon, E. J., Fowler, H. J., Blenkinsop, S., Ferro, C. A. T., and Stephenson, D. B.: Does increasing the spatial resolution of a regional climate model improve the simulated daily precipitation?, Clim. Dynam., 41, 1475-1495, doi:10.1007/s00382012-1568-9, 2013.

Chan, S. C., Kendon, E. J., Fowler, H. J., Blenkinsop, S., Roberts, N. M., and Ferro, C. A.: The value of high-resolution met office regional climate models in the simulation of multi-hourly precipitation extremes, J. Climate, 27, 6155-6174, doi:10.1175/JCLID-13-00723.1, 2014

Christensen, J. H. and Christensen, O. B.: A summary of the PRUDENCE model projections of changes in European climate by the end of this century, Climatic Change 81, 7-30, doi:10.1007/s10584-006-9210-7, 2007.

Demarée, G. R.: Le pluviographe centenaire du plateau d'Uccle: son histoire, ses données et ses applications, La Houille Blanche, 4, 95-102, doi:10.1051/lhb/2003082, 2003.

Deng, H., Luo, Y., Yao, Y., and Liu, C.: Spring and summer precipitation changes from 1880 to 2011 and the future projections from CMIP5 models in the Yangtze River Basin, China, Quatern. Int., 304, 95-106, doi:10.1016/j.quaint.2013.03.036, 2013.

De Troch, R., Hamdi, R., Van De Vyver, H., Geleyn, J.-F., and Termonia, P.: Multiscale performance of the ALARO-0 model for simulating extreme summer precipitation climatology in Belgium, J. Climate, 26, 8895-8915, doi:10.1175/JCLI-D-1200844.1, 2013.

Done, J., Davis, C. A., and Weisman, M.: The next generation of NWP: Explicit forecasts of convection using the Weather Research And Forecasting (WRF) model, Atmos. Sci. Lett., 5, 110117, doi:10.1002/asl.72, 2004.

ECMWF: Climate reanalysis, http://www.ecmwf.int/en/research/ climate-reanalysis, last access: September 2016
European Climate Assessment \& Dataset: E-OBS gridded dataset, http://www.ecad.eu/download/ensembles/download.php, last access: September 2016.

Fosser, G.: Precipitation statistics from regional climate model at resolutions relevant for soil erosion, KIT Scientific Publishing, Karlsruhe, 2014.

Fosser, G., Khodayar, S., and Berg, P.: Benefit of convection permitting climate model simulations in the representation of convective precipitation, Clim. Dynam., 44, 45-60, doi:10.1007/s00382-014-2242-1, 2015.

Fosser, G., Khodayar, S., and Berg, P.: Climate change in the next 30 years: What can a convection-permitting model tell us that we did not already know?, Clim. Dynam., doi:10.1007/s00382-0163186-4, in press, 2016.

Gudmundsson, L., Bremnes, J. B., Haugen, J. E., and EngenSkaugen, T.: Downscaling RCM precipitation to the station scale using statistical transformations - a comparison of methods, Hydrol. Earth Syst. Sci., 16, 3383-3390, doi:10.5194/hess-16-33832012, 2012.

Hamdi, R., Van de Vyver, H., De Troch, R., and Termonia, P.: Assessment of three dynamical urban climate downscaling methods: Brussels's future urban heat island under an A1B emission scenario, Int. J. Climatol., 34, 978-999, doi:10.1002/joc.3734, 2014.

Haylock, M. R., Hofstra, N., Klein Tank, A. M. G., Klok, E. J., Jones, P. D., and New, M.: A European daily high-resolution gridded dataset of surface temperature and precipitation, J. Geophys. Re.-Atmos., 113, D20119, doi:10.1029/2008JD10201, 2008.

Hofstra, N., Haylock, M., New, M., and Jones, P. D.: Testing EOBS European high-resolution gridded data set of daily precipitation and surface temperature, J. Geophys. Res., 144, D21101, doi:10.1029/2009JD011799, 2009.

Hohenegger, C., Brockhaus, P., and Schar, C.: Towards climate simulations at cloud-resolving scales, Meteor. Z., 17, 383-394, doi:10.1127/0941-2948/2008/0303, 2008.

Hong, S. Y. and Leetmaa, A.: An evaluation of the NCEP RSM for regional climate modeling, J. Climate, 12, 592-609, doi:10.1175/1520-0442(1999)012<0592:AEOTNR>2.0.CO;2, 1999.

Ikeda, K., Rasmussen, R., Liu, C., Gochis, D., Yates, D., Chen, F., Tewari, M., Barlage, M., Dudhia, J., Miller, K., Arsenault, K., Grubišić, V., Thompson, G., and Guttman, E.: Simulation of seasonal snowfall over Colorado, Atmos. Res., 97, 462-477, doi:10.1016/j.atmosres.2010.04.010, 2010.

IPCC: The Scientific Basis, in: Contribution of Working Group I to the Third Assessment Report of the Intergovernmental Panel on Climate Change, edited by: Houghton, J. T., Ding, Y., Griggs, D. J., Noguer, M., van der Linden, P. J., Dai, X., Maskell, K., and Johnson, C. A., Cambridge University Press, Cambridge, UK and New York, NY, USA, p. 881, 2001.

IPCC: IPCC Fourth Assessment Report (AR4), Cambridge University Press, Cambridge, 2007.

IPCC: Summary for Policymakers, in: Climate Change 2013: The Physical Science Basis, Contribution of Working Group I to the Fifth Assessment Report of the Intergovernmental Panel on Climate Change, edited by: Stocker, T. F., Qin, D., Plattner, G.-K., Tignor, M., Allen, S. K., Boschung, J., Nauels, A., Xia, Y., Bex, 
V., and Midgley, P. M., Cambridge University Press, Cambridge, UK and New York, NY, USA, 2013.

Jacob, D., Petersen, J., Eggert, B., Alias, A., Christensen, O. B., Bouwer, L. M., Braun, A., Colette, A., Déqué, M., Georgievski, G., Georgopoulou, E., Gobiet, A., Menut, L., Nikulin, G., Haensler, A., Hempelmann, N., Jones, C., Keuler, K., Kovats, S., Kröner, N., Kotlarski, S., Kriegsmann, A., Martin, E., van Meijgaard, E., Moseley, C., Pfeifer, S., Preuschmann, S., Radermacher, C., Radtke, K., Rechid, D., Rounsevell, M., Samuelsson, P., Somot, S., Soussana, J.-F., Teichmann, C., Valentini, R., Vautard, R., Weber, B., and Yiou, P.: EURO-CORDEX: new highresolution climate change projections for European impact research, Reg. Environ. Change, 14, 563-578, doi:10.1007/s10113-0130499-2, 2014.

Johnson, F., Westra, S., Sharma, A., and Pitman, A. J.: An assessment of GCM skill in simulating persistence across multiple time scales, J. Climate, 24, 3609-3623, doi:10.1175/2011JCLI3732.1, 2011.

Kendon, E. J., Roberts, N. M., Senior, C. A., and Roberts, M. $\mathrm{J} .:$ Realism of rainfall in a very high-resolution regional climate model, J. Climate, 25, 5791-5806, doi:10.1175/JCLI-D-1100562.1, 2012.

Kendon, E. J., Roberts, N. M., Fowler, H. J., Roberts, M. J., Chan, S. C., and Senior, C. A.: Heavier summer downpours with climate change revealed by weather forecast resolution model, Nat. Clim. Change, 4, 570-576, doi:10.1038/nclimate2258, 2014.

Maraun, D.: Bias correction, quantile mapping, and downscaling: revisiting the inflation issue, J. Climate, 26, 2137-2143, doi:10.1175/JCLI-D-12-00821.1, 2013.

Maraun, D., Wetterhall, F., Ireson, A. M., Chandler, R. E., Kendon, E. J., Widmann, M., Brienen, S., Rust, H. W., Sauter, T., Themessl, M., Venema, V. K. C., Chun, K. P., Goodess, C. M., Jones, R. G., Onof, C., Vrac, M., and Thiele-Eich, I.:: Precipitation downscaling under climate change: Recent developments to bridge the gap between dynamical models and the end user, Rev. Geophys., 48, RG3003, doi:10.1029/2009RG000314, 2010.

Masson, D. and Knutti, R.: Spatial-scale dependence of climate model performance in the CMIP3 ensemble, J. Climate, 24, 2680-2692, doi:10.1175/2011JCLI3513.1, 2011.

Mayer, S., Maule, C., Sobolowski, S., Christensen, O., Sørup, H., Sunyer, M., Arnbjerg-Nielsen, K., and Barstad, I.: Identifying added value in high-resolution climate simulations over Scandinavia, Tellus A, 67, 24941, doi:10.3402/tellusa.v67.24941, 2015.

Mearns, L. O., Giorgi, F., Whetton, P., Pabon, D., Hulme, M., and Lal, M.: Guidelines for use of climate scenarios developed from regional climate model experiments, Data Distribution Centre of the Intergovernmental Panel on Climate Change, Norwich, UK, 2004.

Mearns, L. O., Sain, S., Leung, L. R., Bukovsky, M. S., McGinnis, S., Biner, S., Caya, D., Arritt, R. W., Gutowski, W., Takle, E., Synder, M., Jones, R. G., Nunes, A. M. B., Tucker, S., Herzmann, D., McDaniel, L., and Sloan, L: Climate change projections of the North American Regional Climate Change Assessment Program (NARCCAP), Climatic Change, 120, 965-975, doi:10.1007/s10584-013-0831-3, 2013.

Ntegeka, C., Baguis, P., Roulin, E., and Willems, P.: Developing tailored climate change scenarios for hydrological impact assessments, J. Hydrol., 508, 307-321, doi:10.1016/j.jhydrol.2013.11.001, 2014.
Olsson, J., Willén, U., and Kawamura, A.: Downscaling extreme short-term regional climate model precipitation for urban hydrological applications, Hydrol. Res., 43, 341-351, doi:10.2166/nh.2012.135, 2012.

Olsson, J., Berg, P., and Kawamura, A.: Impact of RCM spatial resolution on the reproduction of local, subdaily precipitation, J. Hydrometeorol., 16, 534-547, doi:10.1175/JHM-D-14-0007.1, 2015.

Prein, A. F., Gobiet, A., Suklitsch, M., Truhetz, H., Awan, N. K., Keuler, K., and Georgievski, G.: Added value of convection permitting seasonal simulations, Clim. Dynam., 41, 2655-2677, doi:10.1007/s00382-013-1744-6, 2013a.

Prein, A., Holland, G. A., Rasmussen, R. M., Done, J., Ikeda, K., Clark, M. P., and Liu, C. H.: Importance of Regional Climate Model Grid Spacing for the Simulation of Heavy Precipitation in the Colorado Headwaters, J. Climate, 26, 4848-4857, doi:10.1175/JCLI-D-12-00727.1, 2013b.

Prein, A. F., Langhans, W., Fosser, G., Ferrone, A., Ban, N., Goergen, K., Keller, M., Gutjahr, M. T. O., Feser, F., Brisson, E., Kollet, S., Schmidli, J., van Lipzig, N. P. M., and Leung, R. L.: A review on regional convection-permitting climate modeling: demonstrations, prospects, and challenges, Rev. Geophys., 3, 323-361, doi:10.1002/2014RG000475, 2015.

Rajczak, J., Pall, P., and Schär, C.: Projections of extreme precipitation events in regional climate simulations for Europe and the Alpine Region, J. Geophys. Res.-Atmos., 118, 3610-3626, doi:10.1002/jgrd.50297, 2013.

Rana, A., Fostera, K., Bosshard, T., Olsson, J., and Bengtsson, L.: Impact of climate change on rainfall over Mumbai using Distribution-based Scaling of Global Climate Model projections, J. Hydrol. Reg. Stud., 1, 107-128, doi:10.1016/j.ejrh.2014.06.005, 2014.

Rasmussen, R., Liu, C., Ikeda, K., Gochis, D., Yates, D., Chen, F., Tewari, M., Barlage, M., Dudhia, J., Yu, W., Miller, K., Arsenault, K., Grubišić, V., Thompson, G., and Gutmann, E.: Highresolution coupled climate runoff simulations of seasonal snowfall over Colorado: A process study of current and warmer climate, J. Climate, 24, 3015-3048, 2011.

Rauscher, S. A., Coppola, E., Piani, C., and Giorgi, F.: Resolution effects on regional climate model simulations of seasonal precipitation over Europe, Clim. Dynam., 35, 685-711, doi:10.1007/s00382-009-0607-7, 2010.

RMI: Weather Forecast, http://www.meteo.be/meteo/view/en/ 65239-Home.html, last access: September 2016.

Rockel, B., Will, A., and Hense, A.: The Regional Climate Model COSMO-CLM (CCLM), Meteorol. Z., 17, 347-348, doi:10.1127/0941-2948/2008/0309, 2008.

Steppeler, J., Doms, G., Schättler, U., Bitzer, H. W., Gassmann, A., Damrath, U., and Gregoric, G.: Meso-gamma scale forecasts using the nonhydrostatic model LM, Meteorol. Atmos. Phys., 82, 75-96, doi:10.1007/s00703-001-0592-9, 2003.

Sun, Q., Miao, C., and Duan, Q.: Projected changes in temperature and precipitation in ten river basins over China in 21 st century, Int. J. Climatol., 35, 1125-1141, doi:10.1002/joc.4043, 2015.

Sunyer, M. A., Sørup, H. J. D., Christensen, O. B., Madsen, H., Rosbjerg, D., Mikkelsen, P. S., and Arnbjerg-Nielsen, K.: On the importance of observational data properties when assessing regional climate model performance of extreme precipitation, Hy- 
drol. Earth Syst. Sci., 17, 4323-4337, doi:10.5194/hess-17-43232013, 2013.

Sunyer, M. A., Hundecha, Y., Lawrence, D., Madsen, H., Willems, P., Martinkova, M., Vormoor, K., Bürger, G., Hanel, M., Kriaučiūnienè, J., Loukas, A., Osuch, M., and Yücel, I.: Intercomparison of statistical downscaling methods for projection of extreme precipitation in Europe, Hydrol. Earth Syst. Sci., 19, 1827-1847, doi:10.5194/hess-19-1827-2015, 2015.

Tabari, H. and Willems, P.: Daily precipitation extremes in Iran: decadal anomalies and possible drivers, J. Am. Water Resour. As., 52, 541-559, doi:10.1111/1752-1688.12403, 2016.

Tabari, H., AghaKouchak, A., and Willems, P.: A perturbation approach for assessing trends in precipitation extremes across Iran, J. Hydrol., 519, 1420-1427, doi:10.1016/j.jhydrol.2014.09.019, 2014

Tabari, H., Taye, M. T., and Willems, P.: Water availability change in central Belgium for the late 21st century, Global Planet. Change, 131, 115-123, doi:10.1016/j.gloplacha.2015.05.012, 2015.

Tang, Y., Lean, H. W., and Bornemann, J.: The benefits of the met office variable resolution NWP model for forecasting convection, Meteorol. Appl., 20, 417-426, doi:10.1002/met.1300, 2013.

van Haren, R., van Oldenborgh, G. J., Lenderink, G., and Hazeleger, W.: Evaluation of modeled changes in extreme precipitation in Europe and the Rhine basin, Environ. Res. Lett., 8, 014053, doi:10.1088/1748-9326/8/1/014053, 2013. van Pelt, S. C., Beersma, J. J., Buishand, T. A., van den Hurk, B. J. J. M., and Kabat, P.: Future changes in extreme precipitation in the Rhine basin based on global and regional climate model simulations, Hydrol. Earth Syst. Sci., 16, 4517-4530, doi:10.5194/hess16-4517-2012, 2012.

Willems, P.: Compound IDF-relationships of extreme precipitation for two seasons and two storm types, J. Hydrol., 233, 189-205, doi:10.1016/S0022-1694(00)00233-X, 2000.

Willems, P.: A time series tool to support the multi-criteria performance evaluation of rainfall-runoff models, Environ. Model. Softw., 24, 311-321, doi:10.1016/j.envsoft.2008.09.005, 2009.

Willems, P.: Revision of urban drainage design rules after assessment of climate change impacts on precipitation extremes at Uccle, Belgium, J. Hydrol., 496, 166-177, doi:10.1016/j.jhydrol.2013.05.037, 2013.

Willems, P. and Vrac, M.: Statistical precipitation downscaling for small-scale hydrological impact investigations of climate change, J. Hydrol., 402, 193-205, doi:10.1016/j.jhydrol.2011.02.030, 2011.

Willems, P., Arnbjerg-Nielsen, K., Olsson, J., and Nguyen, V.-T.$\mathrm{V}$. .: Climate change impact assessment on urban rainfall extremes and urban drainage: Methods and shortcomings, Atmos. Res., 103, 106-118, doi:10.1016/j.atmosres.2011.04.003, 2012. 